\title{
A survey of cancer pain management knowledge and attitudes of British Columbian physicians
}

\author{
R Gallagher MD CCFP ${ }^{1,2}$, P Hawley MD FRCPC ${ }^{1,2,3}$, W Yeomans MD ${ }^{1,4}$
}

\begin{abstract}
R Gallagher, P Hawley, W Yeomans. A survey of cancer pain management knowledge and attitudes of British Columbian physicians. Pain Res Manage 2004;9(4):188-194.
\end{abstract}

INTRODUCTION: There are many potential barriers to adequate cancer pain management, including lack of physician education and prescription monitoring programs. The authors surveyed physicians about their specific knowledge of pain management and the effects of the regulation of opioids on their prescribing practices.

METHODS: A questionnaire was mailed out to British Columbia physicians who were likely to encounter cancer patients. The survey asked for physicians' opinions about College of Physicians and Surgeons of British Columbia regulation and other issues related to their prescribing practices, and assessed basic knowledge of cancer pain management.

RESULTS: There was a 69\% return rate with a total of 4618 evaluable responses. There was a significant difference among medical disciplines, years in practice, number of chronic pain patients seen and size of community of practice. The highest knowledge scores were achieved by oncologists and the lowest scores were from surgeons. Those who practiced in smaller communities had a higher average knowledge score. Those who felt their knowledge about cancer pain was inadequate scored lower than those who felt their knowledge was adequate. The questions most frequently answered incorrectly (or by "don't know") were those about equianalgesic dosing (68\%) and adequate breakthrough dosing (45\%), revealing knowledge deficiencies that would significantly impair a physician's ability to manage cancer pain. CONCLUSIONS: The details of opioid prescribing are crucial areas to target education for cancer pain management. The surveyed physicians accepted the need for regulation of opioid prescribing with very few being fearful of scrutiny from the College of Physicians and Surgeons of British Columbia. However, the inconvenience of the triplicate prescription pad was more of a barrier to prescribing, it being of concern to $20 \%$ of respondents, particularly surgeons and medical specialists.

Key Words: Cancer; Opioids; Pain; Physicians; Prescribing; Regulation

\footnotetext{
The management of cancer pain has progressed dramatically 1 over the past fifty years. A consensus article on the management of cancer pain in 1941 (1) stated that "the use of narcotics in terminal cancer is to be condemned". The article went on to recommend placebo injections of sterile saline be given, without patient knowledge, to see if pain medication was still needed.
}

\section{Sondage sur les connaissances de la prise en charge des douleurs causées par le cancer et sur les attitudes des médecins britanno- colombiens à cet égard}

\begin{abstract}
INTRODUCTION : Il existe de nombreux obstacles potentiels à une prise en charge convenable de la douleur, y compris le manque de formation de médecins et de programmes de surveillance pharmaceutique. Les auteurs ont interrogé les médecins au sujet de leurs connaissances précises de la prise en charge de la douleur et des effets des règlements sur les opiacés sur leurs pratiques de prescription.
\end{abstract}

MÉTHODOLOGIE : Un questionnaire a été posté aux médecins britannocolombiens susceptibles de voir des patients cancéreux. On y demandait l'avis des médecins quant au règlement du collège des médecins et chirurgiens de la Colombie-Britannique, on y posait d'autres questions reliées à leurs pratiques de prescription et on y évaluait leurs connaissances fondamentales de la prise en charge des douleurs causées par le cancer.

RÉSULTATS : Le taux de retour a été de $69 \%$, pour un total de 4618 réponses évaluables. On remarquait une différence significative dans les disciplines médicales, les années de pratique, le nombre de patients atteints de douleurs chroniques vus et la dimension de la collectivité de pratique. Les indices de connaissances les plus élevés ont été atteints par des oncologues et les plus faibles, par des chirurgiens. Ceux qui exerçaient dans de petites collectivités obtenaient un indice moyen de connaissances plus élevé. Ceux qui avaient l'impression que leurs connaissances au sujet de la douleur reliée au cancer étaient insuffisantes affichaient un indice plus faible que ceux qui jugeaient leurs connaissances suffisantes. Les réponses les plus souvent fausses (ou auxquelles on avait le plus répondu « je ne sais pas ») portaient sur la posologie d'analgésiques équivalents $(68 \%)$ et la posologie des médicaments novateurs (45\%), révélant des déficits de connaissances qui compromettaient considérablement la capacité du médecin à prendre en charge les douleurs reliées au cancer.

CONCLUSIONS : Les détails des prescriptions d'opiacés sont des secteurs cruciaux de formation pour la prise en charge du cancer. Les médecins sondés acceptaient le besoin d'une réglementation des prescriptions d'opiacés, et très peu craignaient les vérifications du collège des médecins et chirurgiens de la Colombie-Britannique. Cependant, l'inconvénient des blocs de prescription en triplicata constituait un plus grand obstacle à la prescription, car il préoccupait $20 \%$ des répondants, surtout des chirurgiens et des spécialistes.

Despite having available and effective medications and treatments, there are still numerous studies reporting inadequately managed cancer pain $(2,3)$. There are many reasons cited for this disparity between what is possible and what happens in reality. A 1995 study (4) interviewing cancer patients with pain found that although $44 \%$ of the patients had poorly controlled pain, $64 \%$ of those patients reported satisfaction with their pain

${ }^{1}$ Division of Palliative Care, University of British Columbia; ${ }^{2}$ British Columbia Cancer Agency; ${ }^{3}$ College of Physicians and Surgeons of British Columbia, Triplicate Prescription Review Committee; ${ }^{4}$ Vancouver Hospital Palliative Care Program, Vancouver, British Columbia

Correspondence and reprints: Dr Romayne Gallagher, Division of Palliative Care, University of British Columbia Hospital, 2211 Wesbrook Mall,

Vancouver, British Columbia V6T 2B5. Telephone 604-822-7784, fax 604-822-1796, e-mail romayne@interchange.ubc.ca 
control. Many patients do not know that their pain can be fully relieved or are concerned about addiction and lack of efficacy, and may not complain about their pain management $(5,6)$. Differences in sex, language and ethnic background also contribute to inadequate analgesia $(7,8)$.

Other studies (9-12) have documented that physician attitudes and knowledge about cancer pain assessment and management have contributed to poor pain management. A 1997 Canadian survey (13) found that $50 \%$ of physicians would not start a patient with severe cancer pain on opioids despite the absence of any contraindications to opioid use. The response rate to this survey was only $17 \%$, with a high probability that those physicians who responded were those who had more interest in the subject than nonresponders; therefore, the actual level of comfort with opioid use in severe cancer pain may have been even lower.

The Division of Palliative Care at the University of British Columbia (UBC) (Vancouver, British Columbia [BC]) has very limited resources and members of the division felt that an assessment of the knowledge of cancer pain management of $\mathrm{BC}$ physicians would be useful in guiding educational initiatives to have the most impact on cancer pain management.

Informal comments to the authors (from both physicians and patients) also suggested that the $\mathrm{BC}$ triplicate prescription program (TPP) may be adversely affecting appropriate opioid prescribing for cancer pain, either because of the inconvenience to physicians of having to use the triplicate pad or because of fear of regulatory scrutiny. A number of American states and Canadian provinces have considered the introduction of multiple copy prescription monitoring programs and declined to do so because of such concerns (14). Some jurisdictions have now switched to electronic data transmission systems to effect regulation without the inconvenience of the triplicate prescription pad (14). No multiple copy prescription monitoring programs have been studied long enough after their inception to allow physicians' initial negative reaction (due to physicians' general resistance to change and perception of increased workload) to have settled, and physicians to have gained a good understanding of the role and intent of the program. There have been no studies in which the issue of regulation was explored separately from the requirement for a multiple copy prescription pad.

The first purpose of the present survey was to acquire current data on physician knowledge and attitudes toward cancer pain management as an educational needs assessment for the UBC Division of Palliative Care. The second was to solicit physicians' opinions about the TPP's possible effect on cancer pain prescribing.

\section{METHODS}

The survey was mailed out under a joint letterhead of the UBC Division of Palliative Care, the BC Cancer Agency and the College of Physicians and Surgeons of BC. Mailing was done using the College of Physicians and Surgeons of BC listing of physicians in the province, and the surveys were mailed to nonspecialist physicians and family physicians, medical specialties (except pathology and laboratory medicine) including pediatrics and all surgical specialties. College identification numbers were used to track who had returned the survey, but support staff removed the number before analysis. A second mailing was sent to nonresponders after three months. The authors were aware that appropriate concerns with regard to the use of opioids for noncancer pain could be reflected in physician opinions and attempted to make it

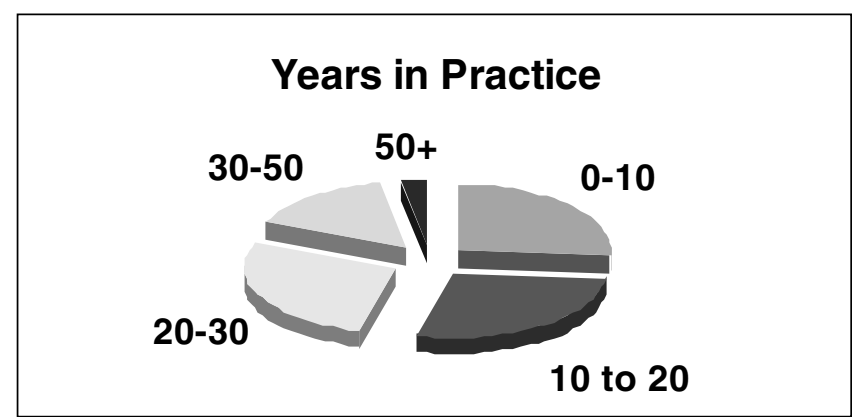

Figure 1) Demographics of the years in practice of the sample

very clear, both on the survey itself and in the covering letter, that cancer pain management was the subject of the survey.

Most of the 'attitude' survey questions were taken from the Texas Cancer Pain Initiative (9) survey, because they had been piloted and would allow some comparison with our study population. Small changes were made in the wording, such as substituting "opioid" for "narcotic". Additional questions that required knowledge essential to competence in the management of chronic pain were developed by the authors, based on their clinical experience as consultants in the management of cancer pain. Other questions or statements were developed by the authors based on their concerns about the TPP. There were 17 questions in total. Eleven of the questions surveyed knowledge and the rest asked for opinions. Demographic questions such as sex, years in practice, size of community in which they work, specialty and number of chronic cancer and noncancer pain patients seen each year were included. Physicians were provided space to make brief comments at the end of the study if they wished to do so. The questions were approved by the College of Physicians and Surgeons of BC before mailing.

The answers were collated and the $\chi^{2}$ test was applied to detect significant differences. The written comments were read by the authors and categorized into comments about the survey, pain management (cancer and noncancer), regulation and the TPP.

\section{RESULTS}

Six thousand eight hundred seventy-five physicians were sent the survey and there was a $42 \%$ initial response. The second mailing yielded a total of 4618 evaluable responses (69\% overall response rate), in which at least one of the questions was answered (95.6\% of returned surveys). Forms returned with no answers $(n=213)$ were usually accompanied by a note stating that the physician had left clinical practice. These forms were given a value of zero. Twenty-five respondents made an attempt to answer the questions but did not answer any knowledge questions correctly. Over two-thirds $(67.9 \%)$ of respondents were male and $27.9 \%$ were female, with $4.2 \%$ surveys with the sex unstated. The experience of the respondents was varied, with $25.3 \%$ in practice for less than 10 years, $26.4 \%$ for 10 to 20 years, $26.2 \%$ for 20 to 30 years and $17.8 \%$ for over 30 years (Figure 1 ). Over onehalf $(61.6 \%)$ of the respondents were family practitioners. Surgical specialties made up $8.1 \%$ of the respondents (Figure 2). One-third of respondents $(32.7 \%$ ) saw more than 30 patients/year with chronic pain, $43.5 \%$ saw between five and 30 patients/year and $18.3 \%$ saw fewer than 10 patients/year (Figure 3). As seen in Figure 4, physicians from all sizes of communities in British Columbia were represented. 


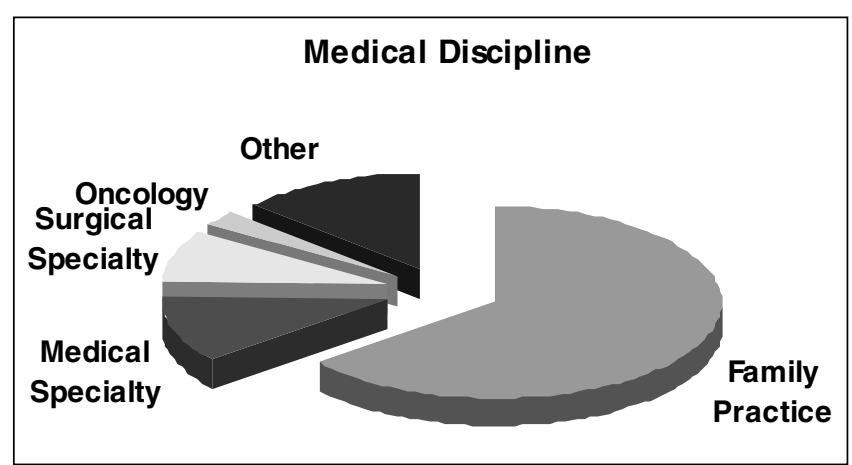

Figure 2) Medical discipline demographics of the sample

\section{Cancer Patients Seen/Year}

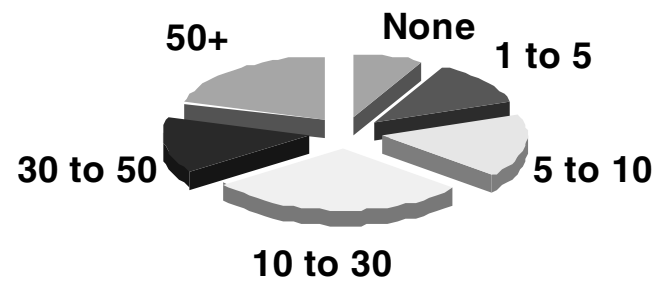

Figure 3) Demographics of the cancer patients seen per year of the sample

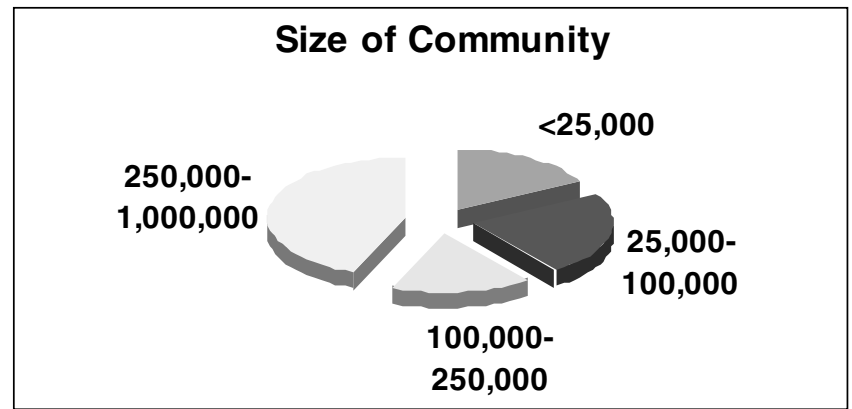

Figure 4) Demographics of the size of the community of the physicians of the sample

The knowledge questions and the responses are listed in Table 1. The average knowledge score was 7.5 out of a maximum of $11(\mathrm{SD} \pm 2.5)$ (Figure 5), and also reflects the 213 individuals who returned the survey with no attempt to answer the questions. Physicians should have been able to answer all the knowledge questions correctly, because these questions only required basic knowledge of cancer pain management.

The question with the most incorrect answers was the one regarding the equivalence of morphine to Tylenol No 3 with Codeine (Janssen-Ortho/McNeil Consumer Healthcare, Canada). Only $31.6 \%$ of respondents answered this question correctly. The question on breakthrough pain was also answered correctly by only $55 \%$ of the physicians. The questions on physical dependence, complaints about pain out of proportion to its cause and increasing requests for analgesics were answered correctly by between $60 \%$ and $70 \%$ of respondents. The question about doses of opioids for breakthrough
TABLE 1

Responses to knowledge questions*

\begin{tabular}{|c|c|c|c|}
\hline Knowledge question & $\begin{array}{l}\text { Truel } \\
\text { agree } \\
\text { n (\%) }\end{array}$ & $\begin{array}{c}\text { Falsel } \\
\text { disagree } \\
\text { n (\%) }\end{array}$ & $\begin{array}{l}\text { Don't } \\
\text { know } \\
\text { n (\%) }\end{array}$ \\
\hline $\begin{array}{l}\text { Any patient who is given opioids for pain } \\
\text { relief is at a } 25 \% \text { or more risk for addiction. }\end{array}$ & $\begin{array}{c}578 \\
(12.0)\end{array}$ & $\begin{array}{l}3546 \\
(73.4)\end{array}$ & $\begin{array}{l}467 \\
(9.7)\end{array}$ \\
\hline $\begin{array}{l}\text { Two tablets of Tylenol No } 3 \text { with Codeine are } \\
\text { are approximately equivalent to } 10 \mathrm{mg} \text { of } \\
\text { oral morphine. }\end{array}$ & $\begin{array}{r}1528 \\
(31.6)\end{array}$ & $\begin{array}{l}2509 \\
(51.9)\end{array}$ & $\begin{array}{c}498 \\
(10.3)\end{array}$ \\
\hline $\begin{array}{l}\text { When switching from oral morphine to } \\
\text { parenteral morphine, I use the } \\
\text { same number of milligrams. }\end{array}$ & $\begin{array}{l}355 \\
(7.3)\end{array}$ & $\begin{array}{l}3827 \\
(79.2)\end{array}$ & $\begin{array}{l}365 \\
(7.6)\end{array}$ \\
\hline $\begin{array}{l}\text { When opioids are taken on a regular basis, } \\
\text { respiratory depression is rare. }\end{array}$ & $\begin{array}{r}3843 \\
(79.5)\end{array}$ & $\begin{array}{c}502 \\
(10.4)\end{array}$ & $\begin{array}{l}234 \\
(4.8)\end{array}$ \\
\hline $\begin{array}{l}\text { Doses of opioid for breakthrough pain } \\
\text { should be } 10 \% \text { of the total daily } \\
\text { dose (every } 1 \mathrm{~h} \text { to } 2 \mathrm{~h} \text { as needed). }\end{array}$ & $\begin{array}{l}2657 \\
(55.0)\end{array}$ & $\begin{array}{c}913 \\
(18.9)\end{array}$ & $\begin{array}{l}967 \\
(20.0)\end{array}$ \\
\hline $\begin{array}{l}\text { Physical dependence while on opioids } \\
\text { is a sign of addiction. }\end{array}$ & $\begin{array}{c}869 \\
(18.0)\end{array}$ & $\begin{array}{r}3298 \\
(68.3)\end{array}$ & $\begin{array}{l}384 \\
(7.9)\end{array}$ \\
\hline $\begin{array}{l}\text { Patients who complain of pain out of } \\
\text { proportion to its cause are usually } \\
\text { substance abusers. }\end{array}$ & $\begin{array}{c}846 \\
(17.5)\end{array}$ & $\begin{array}{c}3122 \\
(64.6)\end{array}$ & $\begin{array}{c}603 \\
(12.5)\end{array}$ \\
\hline $\begin{array}{l}\text { Increasing request for analgesics usually } \\
\text { indicates unrelieved pain. }\end{array}$ & $\begin{array}{l}3323 \\
(68.8)\end{array}$ & $\begin{array}{c}881 \\
(18.2)\end{array}$ & $\begin{array}{l}338 \\
(7.0)\end{array}$ \\
\hline $\begin{array}{l}\text { Morphine for cancer pain shortens life but } \\
\text { makes people more comfortable. }\end{array}$ & $\begin{array}{l}352 \\
(7.3)\end{array}$ & $\begin{array}{c}3894 \\
(80.6)\end{array}$ & $\begin{array}{l}332 \\
(6.9)\end{array}$ \\
\hline $\begin{array}{l}\text { Opioids are not indicated for dyspnea } \\
\text { in patients with advanced cardiopulmonary } \\
\text { disease. }\end{array}$ & $\begin{array}{c}656 \\
(13.6)\end{array}$ & $\begin{array}{r}3442 \\
(71.2)\end{array}$ & $\begin{array}{l}470 \\
(9.7)\end{array}$ \\
\hline $\begin{array}{l}\text { Opioids are the number one cause of } \\
\text { confusion and falls in the elderly patient } \\
\text { and so should not be used until the final } \\
\text { stages of an illness. }\end{array}$ & $\begin{array}{l}300 \\
(6.2)\end{array}$ & $\begin{array}{l}3871 \\
(80.1)\end{array}$ & $\begin{array}{l}421 \\
(8.7)\end{array}$ \\
\hline
\end{tabular}

pain was answered with "don't know" the greatest number of times. The questions answered correctly most frequently were whether morphine for cancer pain shortens life, and whether opioids are the number one cause of confusion and falls in the elderly; both were answered correctly by just over $80 \%$.

Table 2 shows the average knowledge scores in relation to the demographics. The knowledge scores among men and women were not significantly different. Physicians living in smaller communities had significantly higher average scores than those from larger communities $(\mathrm{P}<0.001)$. There was a statistically significant difference in knowledge scores according to the numbers of patients with chronic pain seen per year $(\mathrm{P}<0.001)$. The more patients seen the higher the average scores. Those who believed their knowledge about cancer pain management was adequate scored significantly higher than those who believed that their knowledge was inadequate (8.3 versus 6.7, respectively, $\mathrm{P}<0.001$ ).

The knowledge scores were significantly different among physicians of different specialties. Oncologists had the highest average scores and surgeons had the lowest $(\mathrm{P}<0.001)$. Surgeons were most likely to respond "don't know" on the knowledge questions. Looking at individual knowledge questions, there were significant trends. Family physicians were 


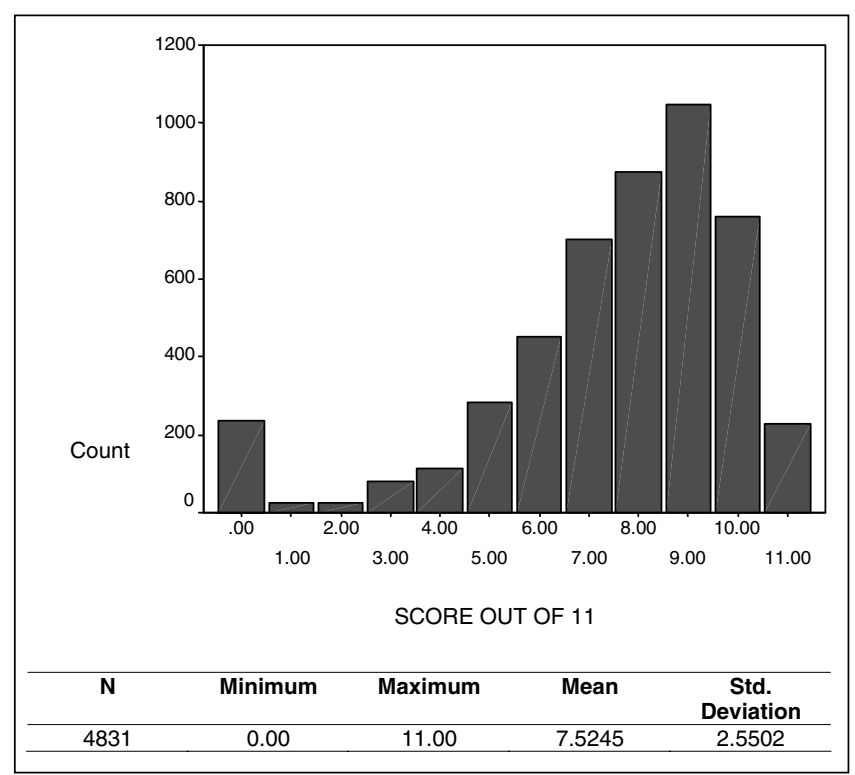

Figure 5) Distribution of knowledge scores

most likely to get the questions on addiction and substance abuse incorrect. Medical specialties scored the lowest on converting oral morphine to parenteral morphine. Surgeons were the most likely to incorrectly state that opioids were the most common cause of falls in the elderly. Both medical and surgical specialties were the most likely to incorrectly agree that opioids are not indicated in the management of dyspnea in advanced lung disease. All were $\mathrm{P}<0.001$.

Seven questions or statements involved attitudes towards cancer pain management and the use of opioids.

"My colleagues are more willing to give opioids for cancer pain than I am."

Almost $73 \%$ of physicians disagreed with this statement, while approximately 20\% answered "don't know". Small numbers of physicians agreed with the statement and they were more likely to be male, live in urban communities and see few cancer patients.

"I believe it is the obligation of all physicians to treat patients with cancer pain or to find another physician who will do this for the patient."

Only 114 (2.4\%) of physicians disagreed with this statement. No demographic category was over-represented in this group.

"If I knew that a prospective patient had cancer pain, I would be uncomfortable accepting that patient."

Only $4.5 \%$ of physicians agreed with this statement. Physicians in large communities who saw few cancer patients were significantly more likely to agree with the statement.

"I believe my knowledge about cancer pain management is adequate to manage almost all of the patients I see."

Forty-nine per cent of physicians felt that their knowledge was adequate, while $35.5 \%$ did not and $10.2 \%$ did not know. A greater proportion of men than women believed that their knowledge about cancer pain management was adequate despite no significant difference between their knowledge scores. Almost $78 \%$ of oncologists felt they had adequate knowledge, and surgeons felt the least confident at $30.2 \%$. Over $58 \%$ of
TABLE 2

Mean knowledge scores by demographics and experience with cancer pain

\begin{tabular}{|c|c|c|}
\hline & Mean & $\mathbf{P}$ \\
\hline Overall & 7.5245 & \\
\hline \multicolumn{3}{|l|}{ Sex } \\
\hline Female & 7.7967 & 0.765 \\
\hline Male & 7.7757 & \\
\hline \multicolumn{3}{|l|}{ Specialty } \\
\hline Family practice & 8.0047 & $<0.001$ \\
\hline Medical specialty & 7.6402 & \\
\hline Surgical specialty & 6.7015 & \\
\hline Oncology & 8.9024 & \\
\hline Other & 7.2797 & \\
\hline \multicolumn{3}{|l|}{ Years in practice } \\
\hline 0 to 10 & 8.0131 & $<0.001$ \\
\hline 11 to 19 & 8.0016 & \\
\hline 20 to 30 & 7.8106 & \\
\hline 30 to 50 & 7.2071 & \\
\hline $50+$ & 6.1719 & \\
\hline \multicolumn{3}{|c|}{ Size of community (population) } \\
\hline$<25,000$ & 8.2028 & $<0.001$ \\
\hline 25,000 to 100,000 & 7.9351 & \\
\hline 100,000 to 250,000 & 7.8035 & \\
\hline 250,000 to 1 million & 7.5705 & \\
\hline \multicolumn{3}{|c|}{ Number of patients with chronic pain/year } \\
\hline None & 5.6154 & $<0.001$ \\
\hline 1 to 5 & 7.1623 & \\
\hline 5 to 10 & 7.6122 & \\
\hline 10 to 30 & 8.1851 & \\
\hline 30 to 50 & 8.2166 & \\
\hline $50+$ & 8.3043 & \\
\hline
\end{tabular}

family physicians felt they had sufficient knowledge and over $39 \%$ of medical specialists agreed. Interestingly, approximately $10 \%$ of physicians from each discipline said they did not know. Belief in one's knowledge about cancer pain management significantly increased with the number of years in practice, except for those in practice over 50 years. Physicians working in larger communities reported significantly less adequate knowledge than their colleagues in smaller centres. As the number of patients with chronic pain seen per year increased, so did the physicians' confidence in their knowledge.

"Having to use a triplicate prescription pad makes me reluctant to use strong opioids."

Twenty per cent of all physicians agreed with this statement, with only $2.5 \%$ answering "don't know". Men agreed significantly more often with this statement than women $(23.4 \%$ versus $17.1 \%$, respectively). Thirty-nine per cent of surgeons agreed that they avoided using opioids due to the triplicate pad, while only $9.8 \%$ of oncologists did. Almost $18 \%$ of family physicians and $24.6 \%$ of medical specialists also admitted having avoided prescribing opioids because of the pad.

"Have you ever felt that you have avoided using opioids to treat cancer pain because of fear of regulatory monitoring?" Over $83 \%$ of physicians disagreed with this statement and only $2.4 \%$ answered "don't know". The responses to this question were statistically significantly different between the sexes 
with $10.7 \%$ of men and $5.9 \%$ of women agreeing. There was no significant difference among disciplines or years in practice; however, as the size of the community increased, significantly more physicians agreed that they have avoided using opioids to treat cancer pain because of fear of regulatory monitoring. Physicians seeing only one to five pain patients/year and those seeing over 50 pain patients/year had significantly more fear of regulatory monitoring $(9.9 \%$ and $11.8 \%$, respectively) than those who saw between five and 50 pain patients/year.

In addition to the above results, $72.5 \%$ of the surveys included written comments, which were very helpful in understanding physicians' opinions in regard to the issues surveyed. Many commented that the survey was useful and welcome. Many offered reasons why their knowledge of cancer pain may not be adequate, including change of the scope of practice, retirement and seeing few patients with cancer.

\section{Comments about the TPP}

Of the 164 respondents who wrote comments specifically about the program, eight were supportive, stating that they felt that the program led to fewer problems with drug seeking. Twelve respondents said that they do not have triplicate pads because their colleagues handle pain management in their patients. Twenty-five respondents offered the opinion that with the advent of a provincial computerized database that tracks all prescriptions in $\mathrm{BC}$, the triplicate program was redundant. One hundred eleven (2.4\% of returned surveys) respondents stated that the triplicate pads were a barrier to prescribing, in addition to answering the specific question on this subject. Helpful suggestions to reduce the work involved in writing a triplicate prescription were also made.

\section{Comments about the College of Physicians and Surgeons of $\mathrm{BC}$}

Fifty-nine respondents made comments about the College of Physicians and Surgeons of BC and its regulation of opioids. Only 21 commented on their reluctance to prescribe opioids due to regulatory monitoring, in addition to answering the specific question on this subject.

Twelve respondents stated that they hoped the College of Physicians and Surgeons of BC could be more involved in education and appreciated the current noncancer pain education programs offered by the regulatory body. Although the survey was clearly directed at cancer pain management, many physicians commented on the difficulties of managing patients with chronic noncancer pain.

\section{DISCUSSION}

The present survey had the limitations of all surveys, in that the information gathered is what respondents say they do, rather than what they actually do on the wards or in their offices. It has been noted that although physicians may display competence (knowledge, positive attitude and skill) in test conditions, their actual practice may not reflect their competence $(15,16)$. Time limitations have a significant impact on the pain management that the patient actually receives, which is independent of the physician's competence displayed when tested under ideal circumstances. Similarly, despite guaranteed anonymity, responses to questions about attitude may reflect what the respondent perceives will be the desired answer, rather than their true opinion.
However, the present survey has the strength of a very high response rate $(69 \%)$, that is considerably better than any other survey of this nature. Those who responded represent the majority of the physicians who would be in the position of managing cancer pain in $\mathrm{BC}$.

Compared to the results from the Texas Cancer Pain Initiative (11), the $\mathrm{BC}$ physicians had a greater number of correct answers and, in general, had less concern about regulatory issues than did their Texan counterparts in 1994. We believe that this reflects an increasing acceptance of opioids as the standard of care for cancer pain over the past decade. Comparing the present survey with a 1995 survey of 145 physicians in Minnesota (10), there were similar high scores in the attitude questions but larger deficits in knowledge in the present sample. The Minnesota study also had a similar difference between specialties, with surgeons having the poorest knowledge.

Although the overall knowledge scores may be considered high, the questions answered incorrectly were key elements to providing adequate analgesia for cancer pain. It is disappointing how many physicians were unaware of analgesic equivalencies between Tylenol No 3 with Codeine and morphine, and were unaware of how to calculate a breakthrough dose. Because this combination product is the most often prescribed analgesic for early stage cancer pain, it suggests that when patients require stronger analgesics, their physician may not be skilled in converting to a more potent opioid. This question was answered incorrectly equally as often by all disciplines, including family practice, anesthesia, surgery and emergency medicine; all specialties that one would expect to deal with this situation on a regular basis. This lack of knowledge points to the need for education that includes case-based calculations of equianalgesic dosing, titration of opioids and calculation of breakthrough doses.

The demographics of the responders suggest that educational initiatives need to be particularly directed toward urban physicians, including both specialists and general practitioners. Although these groups may have better access to specialist oncological and palliative care support than their rural colleagues, they still need the knowledge to be competent in providing basic care. Urban centres tend to have more walk-in clinics and transient patients, giving the average physician less experience with cancer pain management than their rural counterparts.

There was no difference in knowledge scores between male and female physicians; however, men were more confident than women that their knowledge was adequate. Most of the physicians who scored poorly on the knowledge questions seemed to be aware of their lack of knowledge.

Surgeons had the worst knowledge scores of all physicians surveyed, while oncologists had the best scores. This suggests a lack of training in cancer pain management in the surgical residency and continuing surgical education programs. This should be an area for development, because many cancer patients see a surgeon early on in the course of their disease, often when the diagnosis is made. This period is often the pinnacle of distress for patients, as they confront their diagnosis with its ensuing fear of pain and death. Inadequate analgesia at this time may have a profound effect on the patients' experience and expectations, and colour their attitude to subsequent interactions with physicians.

Physicians who saw the most patients with cancer and chronic pain per year had the best knowledge scores. Those who 
saw over 50 pain patients/year were likely to be either palliative care physicians, oncologists or physicians practicing as pain specialists. Interestingly, this group expressed the most concern about the triplicate program and regulatory monitoring. This may be due to awareness of a frequent prescriber status from letters of inquiry about opioid prescribing from the College of Physicians and Surgeons of BC. They would also spend more time writing triplicate prescriptions, so the inconvenience would be greater for them than for those who only use the pad occasionally.

One in five respondents agreed with the statement that "having to use a triplicate prescription pad makes me reluctant to use strong opioids". The triplicate pad also generated the most written comments. Almost $40 \%$ of surgeons stated that the triplicate pad made them reluctant to prescribe strong opioids. Some of this reluctance may also be due to lack of knowledge about pain management, because the knowledge score trends corresponded with reluctance to prescribe due to the triplicate pad.

Fear of college scrutiny is not an issue for the vast majority of physicians (83.6\%). Those in large communities showed significantly more concern than average, possibly because of the high prevalence of the addiction to street drugs and relative anonymity of patients. Those who see more than 50 chronic pain patients/year were also significantly more likely to be concerned about regulatory scrutiny than average. The authors presume that these physicians would be prescribing mainly for chronic noncancer pain and their concern is probably in relation to the regulation of opioid use in this group rather than in cancer patients.

A number of studies $(17,18)$ have shown that the introduction of prescription monitoring programs have reduced the number of prescriptions written for strong opioids ('schedule II' in the United States) in favour of less potent ('schedule III') opioids, which are less suitable for the management of cancer pain. Similar results have been found for benzodiazepines (19-21). Unfortunately, it has been very difficult to assess the impact of these programs on appropriate prescribing and there is some evidence that legitimate patients suffer reduced access to controlled drugs $(22,23)$. The extension of a triplicate prescription monitoring program to include benzodiazepines in New York in 1989 was the best studied program of its kind (21). Followup showed that although the number of benzodiazepine prescriptions fell substantially, prescriptions for other psychoactive medications increased (at least for the first year) and the desired drop in hip fracture rates, benzodiazepine overdoses or hospital admissions in the elderly was not seen. There was also a large (approximately 70\%) drop in the number of benzodiazepine prescriptions during the two months following discharge from hospital after acute cardiac events or acute cancer care (situations where a benzodiazepine may have been appropriate).

Although there have been some excellent reviews on the subject $(19,20,22)$, reports of reduction in diversion and fraud as a result of the introduction of monitoring programs are largely anecdotal $(14,24)$. The drop in total prescriptions seen after the introduction of a monitoring program is likely to consist of a reduction in diversion and fraud, as well as a reduction in appropriate prescriptions. Essentially, the argument in favour of retaining a multiple copy prescription monitoring mechanism rests on the benefit of reduction in prescription forgery weighed against the deterrent to appropriate prescribing, neither of which is easily quantifiable. Further research needs to be done to try to quantify these outcomes. Major American organizations called for more definitive research into these issues in the early 1990s but little has since been published $(24,25)$.

Despite having been in existence for at least 10 years, a significant number of physicians still have negative attitudes to the multiple copy prescription pad. The College of Physicians and Surgeons of $\mathrm{BC}$ does encourage appropriate opioid prescribing and has adopted clinical guidelines for the management of pain, but the prescription data they collect do not have any clinical information. Physicians are contacted on occasion for clinical information relating to either the prescribing for particular patients or as part of a regular review of the current use of particular drugs. The College of Physicians and Surgeons of BC attempts to keep communications with physicians collegial and supportive of appropriate prescribing. Representatives of the College have attended provincial meetings and forums to try to address any concerns about the running of the review program. The triplicate prescription review committee includes physicians currently in specialist pain management practice for cancer and noncancer patients, as well as experts in addiction medicine.

Monitoring programs that require a special multiple copy pad have not been compared with those that are electronically mediated; thus, the issue of regulation per se is not able to be separated from the inconvenience associated with use of the prescription pad. Electronic monitoring systems allow identification of restricted drug dispensing, but forgery would be more difficult to detect without the special pad. In the limited available reports about methods of misuse of prescriptions (24), forgery does not appear to be frequent, even in areas without multiple copy prescription systems. The majority of reported abuse appears to be a result of fraudulent prescribing, fraud related to the dispensing of legitimately obtained prescriptions or misrepresentation by patients, which could be identified as easily by electronic as by multiple copy systems.

Our results suggest that the need for a regulatory program is accepted by the majority of $\mathrm{BC}$ physicians. As electronic systems improve and become part of routine prescription management, opportunities to simplify the pad (or to do away with it altogether) without compromising the effectiveness of the program in preventing harm from drug abuse would be wellreceived by physicians. In the meantime, continuing efforts are required to educate and reassure physicians that appropriate prescriptions for opioid analgesia in cancer patients is encouraged and expected as standard care.

Despite the primary focus of the survey being cancer pain, an area of great concern clearly expressed by physicians' written comments was that of chronic nonmalignant pain. Physicians often stated their need for more support and education in this area and some of the comments suggested that the respondents would welcome College of Physicians and Surgeons of BC involvement. There is no academic department taking responsibility for undergraduate education in chronic noncancer pain at UBC and no graduate specialty accreditation in pain management in Canada. Part of the teaching in palliative care, at both the undergraduate and postgraduate level, concerns noncancer pain management, but there is clearly a need for more education. There is a definite education gap for practicing physicians and provincial colleges of physicians and surgeons may have a valued role to play in facilitating education.

Reports and studies $(26,27)$ have called for penalties for those physicians who do not adequately manage their patients' 
pain. In BC, such an action would require a patient or family member to make a complaint against an individual physician. Patients and families are in a vulnerable position trying to cope with a life-threatening illness such as cancer, and may not be aware of their right to adequate pain management (4).

Further education of physicians (and especially surgeons) is needed if we are to improve cancer pain management in BC. The ability to switch opioids and to calculate breakthrough doses is particularly needed.

Physicians in BC are, in general, not concerned about regulatory scrutiny, but the inconvenience of the triplicate pad itself is seen as a barrier to cancer pain prescribing for a significant number of physicians (one in five), especially surgeons. Electronic methods of prescription monitoring, either without the pad or with a simplified pad, would be well-received and should be combined with education about the role of the review program, to reduce this barrier to good cancer pain management.

DISCLOSURE: Romayne Gallagher receives honoraria for Continuing Medical Education (CME) from Purdue Pharma, Janssen-Ortho and Valeant. Pippa Hawley has received honoraria for CME from a number of pharmaceutical companies including Purdue Pharma and Janssen-Ortho. She also receives honoraria from the College of Physicians and Surgeons of British Columbia for services to the Triplicate Prescription Review Committee. Wendy Yeomans receives honoraria for CME from Purdue Pharma.

FUNDING: The funding for this study was provided from Vancouver Hospital Family Practice Research Fund, through the British Columbia Medical Association.

\section{REFERENCES}

1. Lee LL. Medication in the control of pain in terminal cancer. JAMA 1941;116:216-20.

2. Cleeland CS, Gonin R, Hatfield AK, et al. Pain and its treatment in outpatients with metastatic cancer. New Engl J Med 1994;330:592-6.

3. Hagen N, Young J, MacDonald N. Diffusion of standards of care for cancer pain. CMAJ 1995;152:1205-9.

4. Zhukovsky DS, Gorowski E, Hausdorff J, Napolitano B, Lesser M. Unmet analgesic needs in cancer patients. J Pain Symptom Manage 1995;10:113-9.

5. Ward SE, Berry PE, Misiewicz H. Concerns about analgesics among patients and family caregivers in a hospice setting. Res Nurs Health 1996;19:205-11.

6. Gunnarsdottir S, Donovan HS, Serlin RC, Voge C, Ward S. Patient-related barriers to pain management: The Barriers Questionnaire II (BQ-II). Pain 2002;99:385-96.

7. Anderson KO, Richman SP, Hurley J, et al. Cancer pain management among underserved minority outpatients: Perceived needs and barriers to optimal control. Cancer 2002;94:2295-304.

8. Weiss SC, Emanuel LL, Fairclough DL, Emanuel EJ. Understanding the experience of pain in terminally ill patients. Lancet 2001;357:1311-5.

9. Elliott TE, Elliott BA. Physician attitudes and beliefs about use of morphine for cancer pain. J Pain Symptom Manage 1992; $7: 141-8$
10. Elliott TE, Murray DM, Elliott BA, et al. Physician knowledge and attitudes about cancer pain management: A survey from the Minnesota cancer pain project. J Pain Symptom Manage 1995;10:494-504.

11. Weinstein SM, Laux LF, Thornby JF, et al. Physician's attitudes toward pain and the use of opioid analgesics: Results of a survey from the Texas Cancer Pain Initiative. South Med J 2000;93:479-87.

12. Chow E, Connolly R, Franssen E, et al. Prevalence of under-dosage of analgesics for Cancer Bone Pain in patients referred for palliative radiotherapy, and its potential implications for radiotherapy trials. Ann R Coll Physicians Surg Can 2001;34:217-21.

13. MacDonald N, Findlay HP, Bruera E, Dudgeon D, Kramer J. A Canadian survey of issues in cancer pain management. J Pain Symptom Manage 1997;14:332-42.

14. United States General Accounting Office. Report to the Chairman, Subcommittee on Health, Committee on Ways and Means, House of Representatives. Prescription Drug Monitoring: States Can Readily Identify Illegal Sales and Use of Controlled Substances .

Washington: United States General Accounting Office, 1992. <http://archive.gao.gov/d33t10/147189.pdf> (Version current at October 26, 2004).

15. Eccles M, Ford G, Duggan S, Steen N. Are postal questionnaire surveys of reported activity valid? An exploration using general practitioner management of hypertension in older people. $\mathrm{Br} \mathrm{J}$ Gen Practice 1999;49:35-8.

16. Rethans JJ, Sturmans F, Drop R, van der Vleuten C, Hobus P. Does competence of general practitioners predict their performance. Comparison between examination setting and actual practice. BMJ 1991;303:1377-80.

17. Von Roenn JH, Cleeland CS, Gonin R, Hatfield AK, Pandya KJ. Physician attitudes and practice in cancer pain management: A survey from the Eastern Cooperative Oncology Group. Ann Intern Med 1993;119:121-6.

18. Weissman DE, Joranson DE, Hopwood MB. Wisconsin physicians' knowledge and attitudes about opioid analgesic regulations. Wis Med J 1991;90:671-5.

19. Sigler KA, Guernsey BG, Ingrim NB, et al. Effect of a triplicate prescription law on prescribing of Schedule II drugs. Am J Hosp Pharm 1984;41:108-11.

20. Weissman DE. Doctors, opioids, and the law: The effect of controlled substances regulations on cancer pain management. Semin Oncol 1993;20(Suppl 1):53-8.

21. Weintraub M, Singh S, Byrne L, Maharaj K, Guttmacher L. Consequences of the 1989 New York State triplicate benzodiazepine prescription regulations. JAMA 1991;266:2392-7.

22. Collins TM, Zimmerman DR. Programs for monitoring inappropriate prescribing of controlled drugs: Evaluation and recommendations. Am J Hosp Pharm 1992;49:1765-8.

23. Wastila L, Bishop C. The influence of multiple copy prescription program on analgesic utilization. J Pharm Care Pain Symptom Control 1996;4:3-19.

24. Cooper J, Czechowicz D, Molinari S, Petersen R, eds. Impact of prescription drug diversion control systems on medical practice and patient care. National Institute on Drug Abuse research monograph 131. NIDA Res Monogr 1993;131:1-334. 25. Institute of Medicine, Committee on Opportunities in Drug Abuse Research. Pathways of addiction: Opportunities in Drug Abuse Research. Washington: National Academy Press, 1996.

26. Martino AM. In search of a new ethic for treating patients with chronic pain: What can medical boards do? J Law Med Ethics 1998;26:332-49,263.

27. Field MJ, Cassel CK, eds; Institute of Medicine, Committee on Care at the End of Life. Approaching Death: Improving Care at the End of Life. Washington: National Academy Press, 1997. 


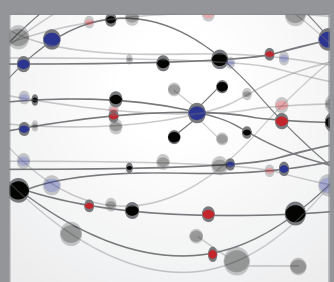

The Scientific World Journal
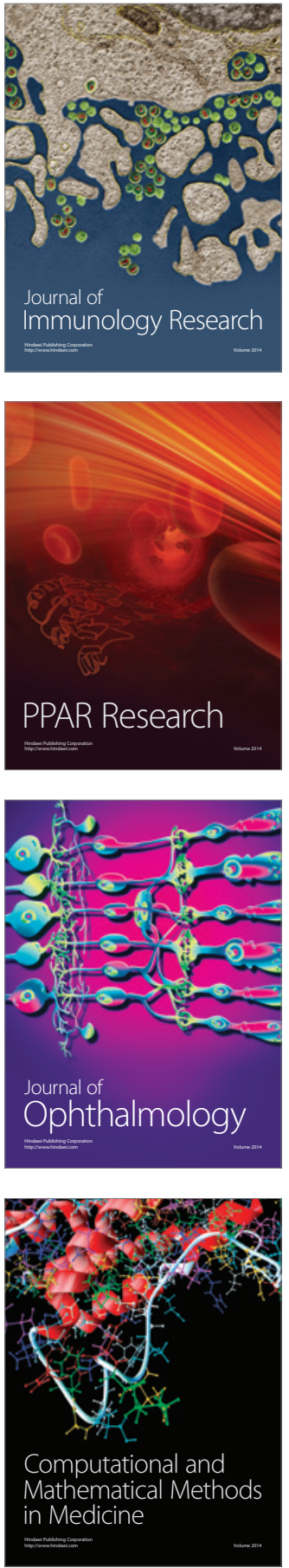

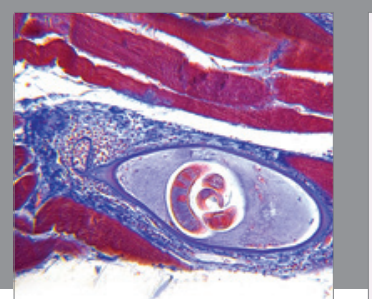

Gastroenterology Research and Practice

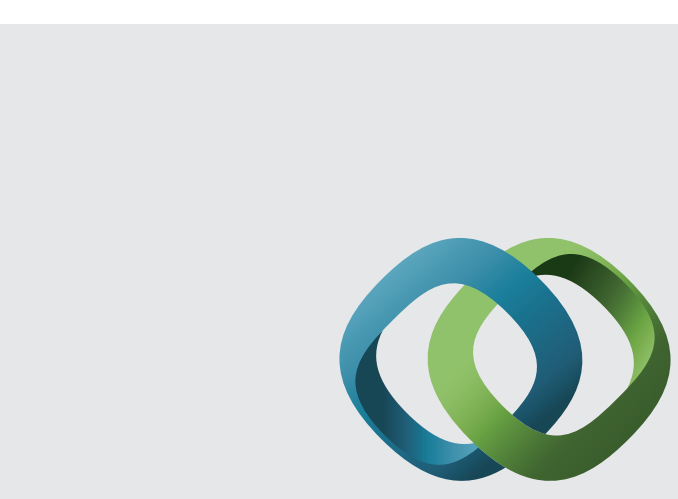

\section{Hindawi}

Submit your manuscripts at

http://www.hindawi.com
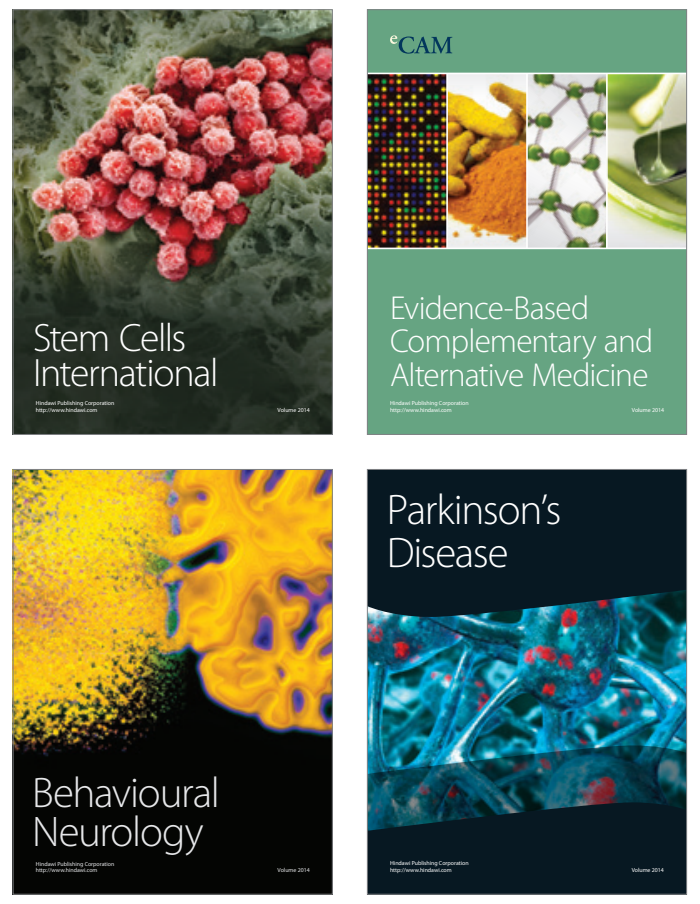
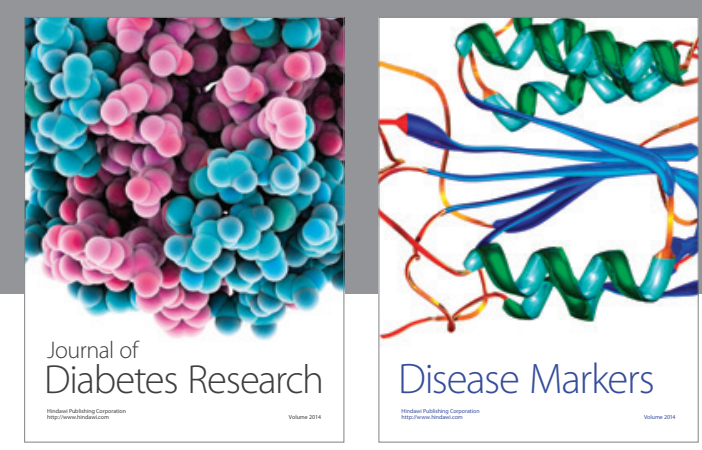

Disease Markers
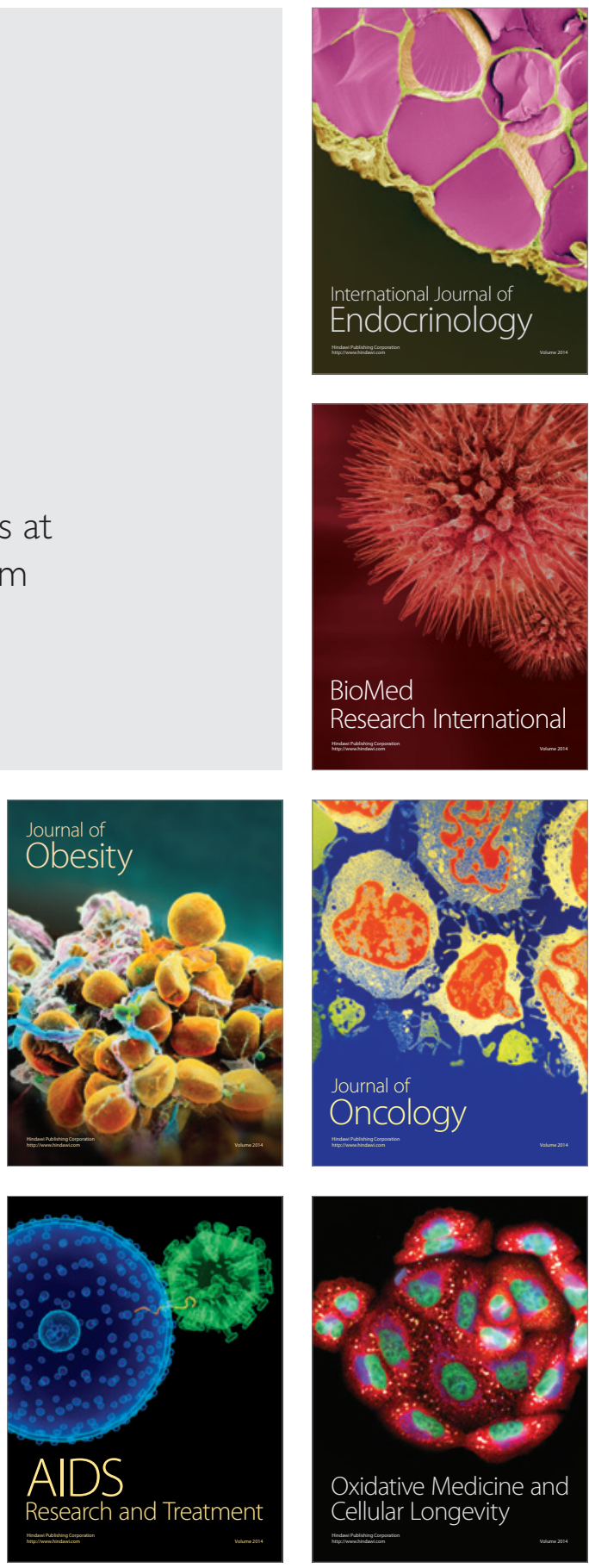